\title{
Antagonism of walnut endophytic bacteria against six crop pathogenic fungi and its diversity
}

\author{
Benzhong Fu ${ }^{1,2 *}$ and Lulu Zou ${ }^{2}$ \\ ${ }^{1}$ College of Life Science and Technology, Hubei Engineering University, Xiaogan, Hubei, China 432000. \\ ${ }^{2}$ Hubei Key Laboratory of Quality Control of Characteristic Fruits and Vegetables, Xiaogan, Hubei, China 432000.
}

Accepted 20 September, 2018

\begin{abstract}
Plant endophytes are great resources and potential capital in versatile application, including plant diseases biocontrol. We aimed to evaluate the antagonism of English walnut endophytic bacteria against different crop pathogenic fungi, to provide more alternatives for future disease biocontrol agents. The biocontrol capacity of thirty-six walnut endophytic bacterial isolates against the anthracnose fungus, Gnomonia leptostyla was evaluated. Fifteen isolates were tested against other five pathogenic fungi such as the cauliflower black spot pathogen, Alternaria brassicicola; the tobacco brown spot pathogen, $A$. alternata; the corn leaf spot pathogen Curvularia lunata; wheat Fusarium head blight pathogen, Fusarium graminearum and the cucumber anthracnose pathogen Colletotrichum orbiculare. From our results, it was observed that all the assayed strains suppressed the growth of six fungal pathogens at least $20 \%$ in petri dish. Among the endophytes, the highest inhibition rates were observed in endophytes XWR6 and XWL14 against $A$. brassicicola with values of 68.8 and $61.6 \%$ respectively; and the endophyte XWS7 against walnut anthracnose pathogen has the inhibition value of $60.5 \%$. Particularly, endophytes XWS7 and XWS4 isolated from walnut stem, showed an inhibition rate above $40 \%$ in all the tested pathogens. Biochemical, physiological and phylogenetic analysis based on 16S-rDNA and gyrB sequences, allowed the identification of the fifteen endophytes at Bacillus spp. However, physiological differences and sequence diversity was observed among the isolates. These findings reveals English walnut endophytic bacteria have strong antagonism activities against crop pathogenic fungi, and show diversity in biochemical, physiological, 16SrDNA and gyrB sequences.
\end{abstract}

Keywords: Walnut, endophyte, walnut anthracnose, antagonism, Bacillus spp.

E-mail: benzhongf@yahoo.com. Tel: +086-13886387573.

\section{INTRODUCTION}

In recent years, plant endophyte has demanded extensive interest in research and development. In general endophytes living in plants without causing any symptoms and obvious harm to the plant, in contrast they can benefit their host by protecting them against pathogens, or promoting plant growth in some cases (Alstrom and Van Vurde, 2001; Adame-lvarez et al., 2014; Ardanov et al., 2012; D’Alessandro et al., 2014). Plant endophytes also could play an important role in reducing pesticides residue and in bioenergy development (Zhang et al., 2014; Afzal et al., 2014).

Several researches in scientific literature have indicated that plant endophytes show potential ability in control of host and non-host plant diseases. For example, strains of Bacillus sp. and Pseudomonas sp. isolated from tomato roots have shown promising results as biocontrol agents for Fusarium oxysporum (Munif et al., 2012). In addition, plant endophytic bacteria show inhibition of spore germination and growth in filamentous fungi, such as Rhizoctonia sp., Colletotrichum orbiculare (Andrieu et al., 2000), and the oomycete palm blight $P$. palmivora (Aramsirirujiwet et al., 2016).

Other important reports indicate that Bacillus megaterium BM1 isolated from wheat grain, inhibits 
wheat Fusarium Head Blight ( $F$. graminearum) mycelia growth and spore germination (Pan et al., 2015). In the crop field test, the disease incidence and deoxynivalenol (DON) toxin are reduced by 54 and $89.3 \%$, respectively (Pan et al., 2015). Centella asiatica endophyte $B$. subtilis BCA31 and $P$. fluorescens BCA08 decreased $C$. higginsianum growth rate by 46 and $82 \%$, respectively (Rakotoniriana et al. 2013). Even more, some crops infected with endophyte attenuated aphids feeding frequently, led to reduce virus infection opportunities indirectly (De Sassi et al., 2006).

Previous research has indicated that walnut endophytic fungi could inhibit several crop pathogens, including cotton blight Rhizoctonia solani, apple anthracnose Gleosporium fructigenum, pear scrab Venturia pirina, wheat head blight $F$. graminearum and rape Sclerotinia rot disease Sclerotinia sclerotiorum mycelial growth, particularly, $100 \%$ inhibition rate on cotton blight (Zhai et al., 2009). The endophytic fungi isolated from walnut root, Coniothyrium vitivora G8, its acetyl acetate extract has inhibition against 4 fungi pathogens: apple ring rot Physalospora piricola, apple canker Valsa ceratosperma, wheat root rot Cochliobolus sativus and rice blast Magnaporthe grisea, the inhibition rate against these 4 fungi pathogens were all $100 \%$ (Xu et al., 2008). It has been observed that walnut endophyte HT-6 fermentation broth against mycelial growth of pepper anthracnose, walnut and apple canker at $80 \%$ inhibition rate, suppress spore germination of pear black spot, tomato gray mold and pepper anthracnose pathogens at $100 \%$ inhibition rate (Wu et al., 2015).

In this paper, thirty-six endophytic bacteria were isolated and identified from two-year old walnut Juglans regia roots, stems and leaves. The biocontrol capacity of the isolates identified against anthracnose fungus, Gnomonia leptostyla were evaluated. Another fifteen isolates were tested also against other five pathogenic fungi such as Alternaria brassicicola, $A$. alternata, Curvularia lunata, $F$. graminearum and $C$. orbiculare. Biochemical, physiological and phylogenetic analysis based on 16S-rDNA and gyrB sequences was conducted as well.

\section{MATERIALS AND METHODS}

\section{Isolation of walnut endophytes}

Samples were obtained from two years old healthy walnut plants. Tissue of roots, stems and leaves were analyzed. In the case of roots and stems, the outer cortex was scratched and cut into $2 \mathrm{~cm} \times$ $2 \mathrm{~cm}$ patches. Samples were disinfected with $0.1 \%$ mercury chloride $(\mathrm{HgCl})$ and $75 \%$ alcohol and washed with double deionized water $\left(\mathrm{ddH}_{2} \mathrm{O}\right)$ for five times. The final flushed water and tissue was spread onto Nutrient Agar medium as control to check the surface disinfection effect. Samples were collected in tubes with $1 \mathrm{ml}$ $\mathrm{dd}_{2} \mathrm{O}$, and crushed with sterilized tweezers and incubated for 20 min and $200 \mu \mathrm{l}$ were spread onto NA medium with three replicates, which were incubated at $26^{\circ} \mathrm{C}$ for $2-5$ days. Colonies were selected based on different size and color, re-streaked and stored in $30 \%$ glycerol at $-80^{\circ} \mathrm{C}$.

\section{Targeting fungi pathogens}

Isolates of $G$. leptostyla and $A$. brassicicola were collected in our laboratory. Tobacco brown spot $A$. alternata, cucumber anthracnose $C$. orbiculare, corn leaf spot pathogen $C$. lunata, wheat Fusarium head blight $F$. graminearum strains were provided by Hubei Academe of Agricultural Sciences.

\section{Plate confrontation test}

The plate confrontation test was conducted on NA medium plates. The target fungi were inoculated as $6 \mathrm{~mm}$ diameter plugs in the center of the plates and endophytic bacteria into the plate with a distant of $30 \mathrm{~mm}$. Plates without endophytic bacteria were used as controls. Plates were incubated at $26^{\circ} \mathrm{C}$, until the control mycelium grow to the endophyte inoculation point. Inhibitory effects were analyzed by measuring the mycelial growth radius, inhibition radius and minimum Interval Distance (ID, $\mathrm{mm}$ ) between the pathogen and the endophyte margins. Each experiment was set in five plates, and the experiments were repeated three times. The inhibition rate was calculated based on the following formula:

Inhibition rate $(\%)=($ control radius-treated radius $) /($ control radius 3) $\times 100$.

Clustering based on biochemical and physiological characteristics

The biochemical and physiological characteristics of fifteen strains were tested according to the protocols described in Dong (Dong and Cai, 2001). We conduct the following tests: v-p test, starch hydrolysis, indole produce, urase, acetic acid oxidation, citric acid salt, methyl red, catalase, celluolase, oxidase, anti-nitrification, pyovendin, milk liquefaction, motility, ethanol oxidation, gelatin liquefaction, salt tolerance. Results were recorded and saved in binary format table (1 represented for positive, 0 represented negative or uncertain). Clustering was conducted using the NTSYSpc2.1 software.

\section{Phylogenetic tree construction based on16S-rDNA and gryB gene sequences}

Bacterial DNA was extracted using TaKaRa DNA Extraction Kit. DNA degradation and quality and quantification were tested by visualizing samples in $1.5 \%$ agarose gel electrophoresis and Nanodrop assay. Amplification of $16 \mathrm{~S}$ rDNA was conducted using primers: $27 \mathrm{~F}\left(5^{\prime}-A G A G T T T G A T C C T G G C T C A G-3\right.$ ') and 1492R(5'GGTTACCTTGTTACGACTT-3'). PCR reaction was prepared according to Pre Mix (Sangon biotech, Shanghai) manual, and cycles with $94^{\circ} \mathrm{C} 5 \mathrm{~min}, 94^{\circ} \mathrm{C} 50 \mathrm{~s}, 57^{\circ} \mathrm{C} 1 \mathrm{~min}, 72^{\circ} \mathrm{C} 90 \mathrm{~s}, 34$ cycles, $72^{\circ} \mathrm{C} 10 \mathrm{~min}$. The amplification of $g y r \mathrm{~B}$ gene was conducted using primers: gyrBF 5'-GAAGTCATCATGACCGTTCTGCAYGGN GGNAARTTYGA-3' and gyrBR 5'-AGCAGGCTACGGATGTGCGA GCCRTCNACRTCNGCKTCNGTCAT-3', PCR reaction compositions and thermal cycles were in accordance to the method described by the company's manual.

The PCR products were detected on $1.5 \%$ agarose gel and sequenced in both directions. The identity of the sequences was conducted by comparing nucleotide with the GenBank database. Phylogenetic tree was constructed using MEGA 7. 0 software with Neighbor-Joining method using a bootstrap $=1000$ (Saitou and Nei, 1987). 


\section{RESULTS}

\section{Effect of walnut endophytes against host pathogen G. leptostyla HK1}

We isolated a total of 36 endophytic bacteria, 8 strains from roots, accounted $22.2 \%$, and code with XWR and number, 12 strains from stems, accounted $33.3 \%$, code with XWS and number, 16 strains from leaves, accounted $44.4 \%$, code with XWL and number.

Our results showed that all of the endophytes have an antagonistic effect on $G$. leptostyla HK1.The minimum inhibition rate was $24.2 \%$. Among which, 4 strains showed an inhibition rate of $20.0-29.9 \%$, 8 strains 30.0 to $39.9 \%$, 21 strains 40.0 to $49.9 \%$. Strains SWS1 and XWS4 showed inhibition rates above $50.0 \%$. The highest inhibition rate was observed in strain XWS4 $(60.5 \%)$ (Table 1). All the strains that showed inhibition rates higher than $50 \%$ were isolated from stems. Strain XWR8 isolated from roots showed an inhibition rate of $49.3 \%$ which also has the highest Interval Distance of $3.5 \mathrm{~mm}$.

Based on colony morphology and antagonistic results, fifteen endophytes were chosen for further investigation on other five crop pathogens.

\section{Antagonistic effect of endophytes against} cauliflower black spot pathogen A. brassicicola

All the tested fifteen endophytes showed a strong antagonistic effect on $A$. brassicicola mycelial growth. The inhibition rates were higher than $30 \%$. Among of them, 12 endophytes show inhibition rate above 50\%. Strains XWL14 and XWR6 showed the highest antagonistic effect. Their inhibition rates were higher than $60 \%$, and the Interval Distance is higher than $4 \mathrm{~mm}$ (Table 2). Strain XWR6 showed the strongest antagonistic effect, the rate reached $68.8 \%$. These results suggested that the pathogen was very sensitive to walnut endophytic bacteria.

\section{Antagonistic effect of endophytes against tobacco brown spot pathogen A. alternata}

All tested fifteen endophytes showed an antagonistic effect on the pathogen $A$. alternata in petri dish. The inhibition rates were between 22.0 to $48.0 \%$, among of them, 10 strains show inhibition rate between 30 and $40 \%$. Three strains XWS13, XWS4 and XWS7 showed the highest antagonistic effect. Their inhibition rates were higher than $40 \%$, and the Interval Distance is higher than $4 \mathrm{~mm}$ (Table 3). Strain XWS7 showed the strongest antagonistic effect, the rate reached $48.0 \%$.

\section{Antagonistic effect of endophytes against} cucumber anthracnose pathogen $C$. lagenarium

All the tested fifteen endophytes showed antagonistic effect on $C$. lagenarium growth, their values range from 22.4 to $54.8 \%$ (Table 4). Among them, 8 endophytes range from 30 to $40 \%, 5$ endophytes above $40 \%$. Strain XWS3 showed the strongest antagonistic effect, the inhibition rate was $54.8 \%$.

\section{Antagonistic effect of endophytes against corn leaf spot pathogen $C$. lunata}

All tested fifteen endophytes showed a moderate

Table 1. Inhibition rates of 36 walnut endophytic bacteria on the anthracnose pathogen HK1.

\begin{tabular}{|c|c|c|c|c|c|c|c|c|c|c|c|c|}
\hline Strains & XWL9 & XWL13 & XWL15 & XWL18 & XWL10 & XWS8 & XWR7 & XWR3 & XWL5 & XWS10 & XWS5 & XWL8 \\
\hline IR (\%) & 24.2 & 27.4 & 29.4 & 29.5 & 32.6 & 36.1 & 37.5 & 37.9 & 38.6 & 38.8 & 39.4 & 39.7 \\
\hline ID (mm) & 0.0 & 0.0 & 0.3 & 1.1 & 0.3 & 1.4 & 0.2 & 2.3 & 3.3 & 0.8 & 0.5 & 0.7 \\
\hline Strains & XWS12 & XWS9 & XWL3 & XWS3 & XWS11 & XWL4 & XWR4 & XWL11 & XWL6 & XWS2 & XWR2 & XWL7 \\
\hline IR (\%) & 40.9 & 41.3 & 41.9 & 42.4 & 42.4 & 44.3 & 44.8 & 44.9 & 45.0 & 45.0 & 45.0 & 45.4 \\
\hline ID (mm) & 0.7 & 0.6 & 2.8 & 2.0 & 0.8 & 2.2 & 1.3 & 1.4 & 3.3 & 1.4 & 2.5 & 2.1 \\
\hline Strains & XWS13 & XWR1 & XWL17 & XWL14 & XWR5 & XWR6 & XWL12 & XWR8 & XWL16 & XWS1 & XWS4 & XWS7 \\
\hline IR (\%) & 45.9 & 46.0 & 46.0 & 46.3 & 47.7 & 48.8 & 48.9 & 49.3 & 49.6 & 50.3 & 52.1 & 60.5 \\
\hline ID (mm) & 2.2 & 2.5 & 2.1 & 0.8 & 0.9 & 1.3 & 1.1 & 3.5 & 1.2 & 0.6 & 1.3 & 0.7 \\
\hline
\end{tabular}


Table 2. Inhibition rates of walnut endophytic bacteria oncauli flower black spot pathogen.

\begin{tabular}{lccccc}
\hline Strains & XWS11 & XWS12 & XWS10 & XWR5 & XWS4 \\
IR $(\%)$ & 31.5 & 32.0 & 34.5 & 50.3 & 51.6 \\
ID $(\mathrm{mm})$ & 0.7 & 1.0 & 0.5 & 5.8 & 3.3 \\
& & & & & \\
Strains & XWS7 & XWS1 & XWS3 & XWL17 & XWR1 \\
IR (\%) & 52.8 & 53.7 & 54.7 & 55.8 & 57.0 \\
ID $(\mathrm{mm})$ & 1.6 & 5.5 & 7.1 & 5.0 & 9.9 \\
& & & & & \\
Strains & XWS13 & XWL12 & XWL16 & XWL14 & XWR6 \\
IR $(\%)$ & 57.2 & 57.8 & 58.9 & 61.6 & 68.8 \\
ID $(\mathrm{mm})$ & 6.4 & 6.1 & 5.7 & 4.9 & 4.0 \\
\hline
\end{tabular}

Table 3. Inhibition rates of walnut endophytic bacteria on tobacco brown spot pathogen.

\begin{tabular}{lccccc}
\hline Strains & XWS10 & XWS11 & XWL17 & XWS12 & XWR5 \\
IR $(\%)$ & 22.0 & 28.4 & 30.7 & 32.4 & 32.7 \\
ID $(\mathrm{mm})$ & 0.0 & 0.1 & 0.9 & 0.0 & 0.9 \\
& & & & & \\
Strains & XWR6 & XWS1 & XWL16 & XWL12 & XWL14 \\
IR $(\%)$ & 32.9 & 35.7 & 37.0 & 37.1 & 38.0 \\
ID $(\mathrm{mm})$ & 1.2 & 1.5 & 0.6 & 1.0 & 1.6 \\
& & & & & \\
Strains & XWR1 & XWS3 & XWS13 & XWS4 & XWS7 \\
IR $(\%)$ & 38.2 & 38.3 & 41.5 & 44.0 & 48.0 \\
ID $(\mathrm{mm})$ & 3.4 & 3.0 & 2.3 & 0.7 & 1.0 \\
\hline
\end{tabular}

Table 4. Inhibition rates of 15 walnut endophytic bacteria on cucumber anthracnose pathogen.

\begin{tabular}{lccccc}
\hline Strains & XWS10 & XWL17 & XWS12 & XWS1 & XWL12 \\
IR $(\%)$ & 22.4 & 28.4 & 30.0 & 30.6 & 30.8 \\
ID $(\mathrm{mm})$ & 0.0 & 0.7 & 0.0 & 0.8 & 0.5 \\
& & & & & \\
Strains & XWL14 & XWR6 & XWS3 & XWS11 & XWL16 \\
IR $(\%)$ & 32.3 & 33.8 & 35.9 & 37.1 & 37.9 \\
ID $(\mathrm{mm})$ & 0.0 & 0.3 & 2.9 & 1.0 & 0.8 \\
& & & & & \\
Strains & XWR5 & XWS4 & XWS7 & XWR1 & XWS13 \\
IR $(\%)$ & 40.8 & 42.9 & 43.3 & 48.4 & 54.8 \\
ID $(\mathrm{mm})$ & 0.4 & 0.1 & 0.0 & 0.3 & 0.0 \\
\hline
\end{tabular}

antagonistic effect on $C$. lunata mycelial growth. The inhibition rates were from 25.8 to $48.7 \%$ (Table 5). Among of them, 9 endophytes were between 30 and $40 \%, 5$ endophytes were above $40 \%$. The endophytes effect above $40.0 \%$ were all isolated from walnut roots and stems.
Antagonistic effect of endophytes against wheat head blight pathogen $F$. graminearum

All tested fifteen endophytes against $F$. graminearum showed antagonistic effect in some degree, the inhibition rates were higher than $30 \%$. And 6 of them showed 
Table 5. Inhibition rates of walnut endophytic bacteria on corn leaf spot pathogen.

\begin{tabular}{lccccc}
\hline Strains & XWS12 & XWS11 & XWL17 & XWS3 & XWS10 \\
IR $(\%)$ & 25.8 & 30.1 & 30.4 & 33.0 & 33.5 \\
ID $(\mathrm{mm})$ & 0 & 0 & 2.2 & 0.6 & 0 \\
& & & & & \\
Strains & XWL12 & XWS13 & XWL14 & XWL16 & XWR6 \\
IR (\%) & 34.8 & 34.9 & 35.1 & 36.7 & 39.0 \\
ID (mm) & 2.3 & 0.7 & 0.9 & 2.4 & 0.8 \\
& & & & & \\
Strains & XWS4 & XWR5 & XWR1 & XWS1 & XWS7 \\
IR (\%) & 40.6 & 41.1 & 42.0 & 46.7 & 48.7 \\
ID (mm) & 1.1 & 2.8 & 0.8 & 1.2 & 0.8 \\
\hline
\end{tabular}

Table 6. Inhibition rates of walnut endophytic bacteria on F. graminearum.

\begin{tabular}{lccccc}
\hline Strains & XWS12 & XWS10 & XWS13 & XWR5 & XWS11 \\
IR (\%) & 31.8 & 32.4 & 35.7 & 35.8 & 37.6 \\
ID $(\mathrm{mm})$ & 0.0 & 0.0 & 0.2 & 0.9 & 0.0 \\
& & & & & \\
Strains & XWS1 & XWL12 & XWR6 & XWL17 & XWR1 \\
IR (\%) & 38.2 & 39.4 & 39.8 & 39.8 & 40.2 \\
ID (mm) & 0.5 & 2.4 & 1.0 & 1.5 & 0.8 \\
& & & & & \\
Strains & XWS4 & XWS3 & XWL16 & XWS7 & XWL14 \\
IR (\%) & 41.3 & 42.3 & 43.0 & 44.8 & 45.1 \\
ID (mm) & 0.4 & 0.0 & 1.1 & 0.5 & 1.9 \\
\hline
\end{tabular}

above $40 \%$ (Table 6). Among of them, strain XWL14 isolated from walnut leaf, showed the highest inhibition rate and the biggest Interval Distance with $45.1 \%$, and $1.9 \mathrm{~mm}$ respectively.

\section{Integrated evaluation of walnut endophytes antagonist against 6 crop pathogenic fungi}

The detected thirty-six walnut endophytes capacity is against its anthracnose pathogen $G$. leptostyla HK1, and fifteen of them are against 5 crop pathogenic fungi. The inhibition rates (total 111 values) were from the lowest, $22.0 \%$ to the highest $68.8 \%, 9$ values in 20.0 to $29.9 \%$, accounting for $8.1 \%$; 47 values in 30 to $40 \%$, accounting for $42.3 \%$, 39 values in 40 to $50 \%$, accounting for $35.2 \%$; 13 values in 50 to $60 \%$, accounting for $11.7 \%$. These results indicated that walnut endophytes have abroad antimicrobial spectrum and application potential (Figure 1).Three inhibition rates were higher than $60 \%$, strain XWS7 against HK1, stains SWR6 and SWL14 against tobacco brown spot pathogen $A$. alternata. Amongst the six target fungal pathogens, $A$. brassicicola was the most susceptible, $80 \%$ tested endophytes showed inhibition rates above than $50 \%$. The endophytes of walnut against the host pathogen showed significant role, two-thirds of inhibition rates were above $40 \%$.

Fifteen endophytes antagonistic abilities were evaluated. Inhibition rates 40.0 to $49.9 \%$, marked with $\Delta$, 50.0 to $59.9 \%$ marked with $\square$, higher than $60.0 \%$ marked with - (Table 7). Based on this evaluation, strains XWS7 and XWS4 showed the highest antagonistic effects, all inhibition rates were higher than $40 \%$. Subsequently strain XWR1 is against 5 target fungi with inhibition rates higher than $40 \%$.

\section{Clustering of walnut endophytes based on biochemical and physiological characteristics}

Seventeen biochemical or physiological characters of fifteen walnut endophytic bacteria were assayed. Based on their positive or negative reactions, we convert them into 1 or 0 binary table. We constructed a cladogram using NTSYSpc2.1 software (Figure 2). The highest similarity was $94 \%$, the lowest was $57 \%$. The endophytic bacteria could be divided into six clades based on $76 \%$ coefficient. These results implied that the endophytes have abundant diversity. The most effective strains, XWS7, XWS4 and XWR1 belong to 3 different clades, 


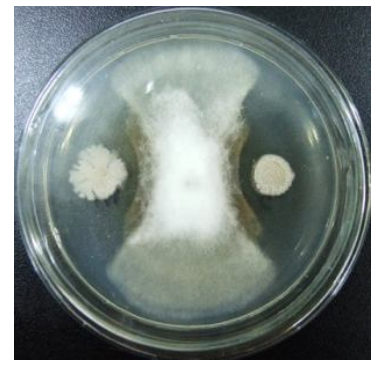

XWR1-HK1

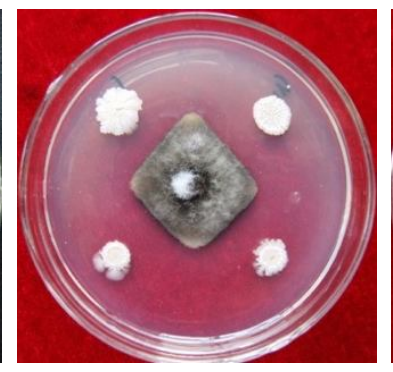

XWR1 - A. brassicicola

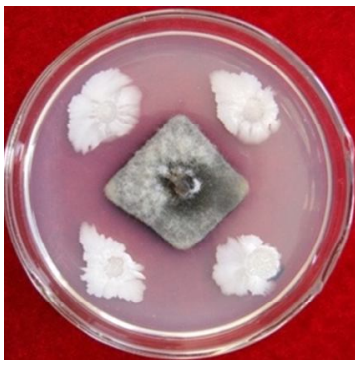

XWR2 - A. brassicicola

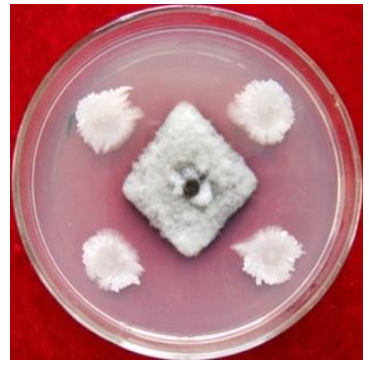

XWS3 - A. brassicicola

Figure 1. Antagonism of walnut endophytic bacteria againstcrop fungal pathogens.

Table 7. Inhibitory talent comparison of 15 walnut endophytic bacteria on 6 plant fungal pathogens.

\begin{tabular}{lcccccc}
\hline Endophyte & HK1 & C. lunata & A. alternata & C. orbiculare & F. graminearum & A. brassicicola \\
\hline XWS7 & $\square$ & $\Delta$ & $\Delta$ & $\Delta$ & $\Delta$ & $\square$ \\
XWS4 & $\square$ & $\Delta$ & $\Delta$ & $\Delta$ & $\Delta$ & $\square$ \\
XWR1 & $\Delta$ & $\Delta$ & & $\Delta$ & $\Delta$ & $\square$ \\
XWS13 & $\Delta$ & & $\Delta$ & $\square$ & & $\square$ \\
XWR5 & $\Delta$ & $\Delta$ & & $\Delta$ & $\Delta$ & $\square$ \\
XWS1 & $\square$ & $\Delta$ & & & $\Delta$ & $\square$ \\
XWL14 & $\Delta$ & & & & & $\square$ \\
XWS3 & $\Delta$ & & & & & $\square$ \\
XWL16 & $\Delta$ & & & & & $\square$ \\
XWR6 & $\Delta$ & & & & & $\square$ \\
XWL12 & $\Delta$ & & & & & \\
XWL17 & $\Delta$ & & & & & $\square$ \\
XWS11 & $\Delta$ & & & & & \\
XWS12 & $\Delta$ & & & & & \\
XWS10 & & & & & & \\
\hline
\end{tabular}

Note: $\Delta$ means inhibition rates between 40.0 and $49.9 \%$, 口means inhibition rates between $50.0 \%$ and $59.9 \%$,

means inhibition rates $\geqq 60.0 \%$, blank means inhibition rates less than $40 \%$.

which indicated that they could not differentiate their antagonistic bacteria efficiency by these biochemical or physiological assayed characteristics.

\section{Phylogenetic tree of based on 16S rDNA and gyrB sequences}

The sequence analysis of the 16S rDNA and gyrB genes indicated that all the 15 endophytes attributed to Bacillus spp. which is a big group of endophytic plants (Figure 3). Strain XWL17 shows $99 \%$ identity to B. pumilus, Strain XWS3, XWS4, XWS12 and XWR5 show 99\% identity to $B$. subtilis and $B$. tequilensis. Strains XWL12, XWS7, XWS11, XWL14 and XWR1 were clustered in one clade, sequences analysis showed $99 \%$ identity to $B$. subtilis and $B$. tequilensis. However, based on independent gyrB gene sequence analysis, all the 15 strains have highest identity with $B$. subtilis. Besides, these strains could not be clustered into different groups according to isolated tissues or their antagonistic abilities.

\section{DISCUSSION}

In this study, the thirty-six endophytes were isolated from the root, stem and leaf of walnut. The strains were tested against walnut anthracnose pathogens, and fifteen of the strains were chosen to test their antagonistic effect against five no-host pathogens. All the assayed results showed inhibition phenomena in some degree. The inhibition rates of strains XWR6 and XWL14 against cauliflower black spot pathogen $A$. brassicicola, the highest 68.8 and $61.6 \%$ respectively. The inhibition rate of strain XWS7 against host walnut anthracnose pathogen G. leptostyla HK1 was $60.5 \%$. The strains 


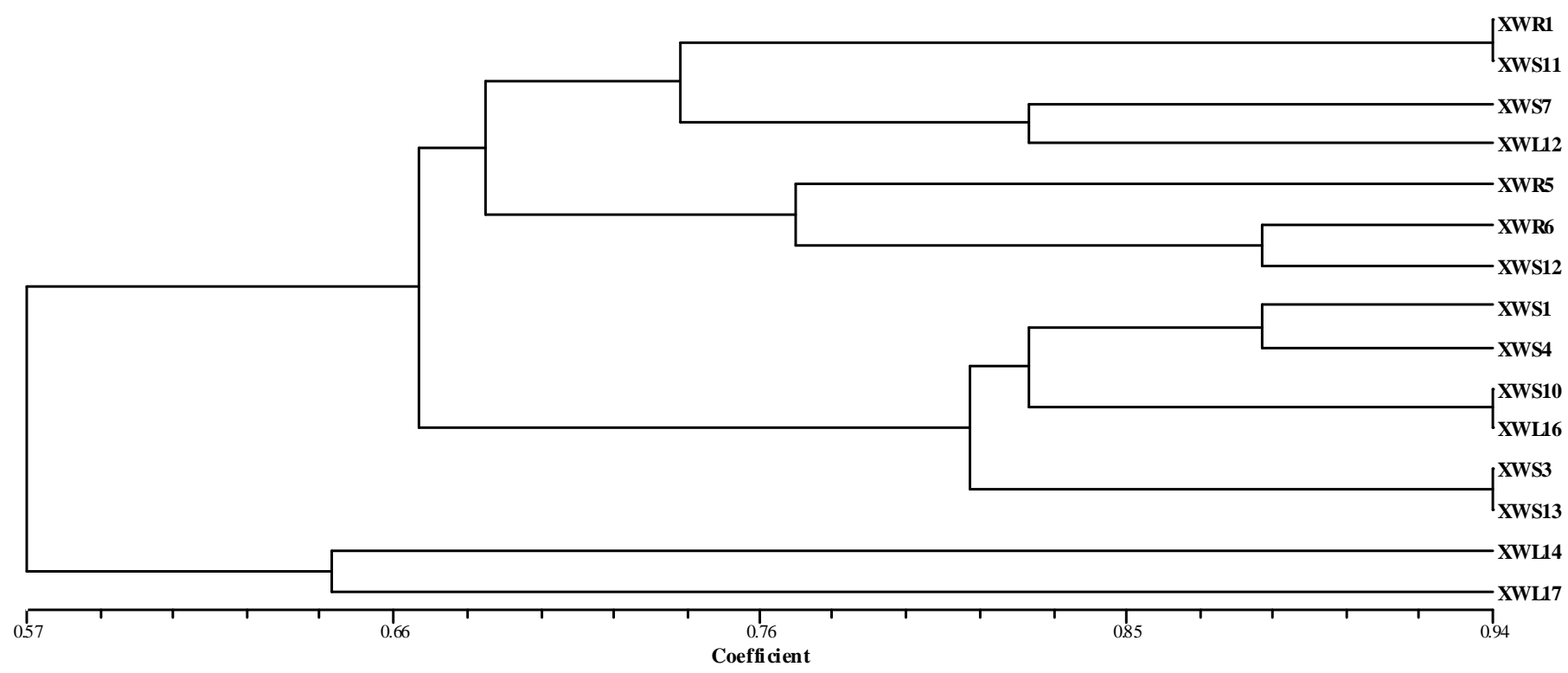

Figure 2. Cluster tree of fifteen walnut endophytic bacteria based on biochemical and physical profiles.

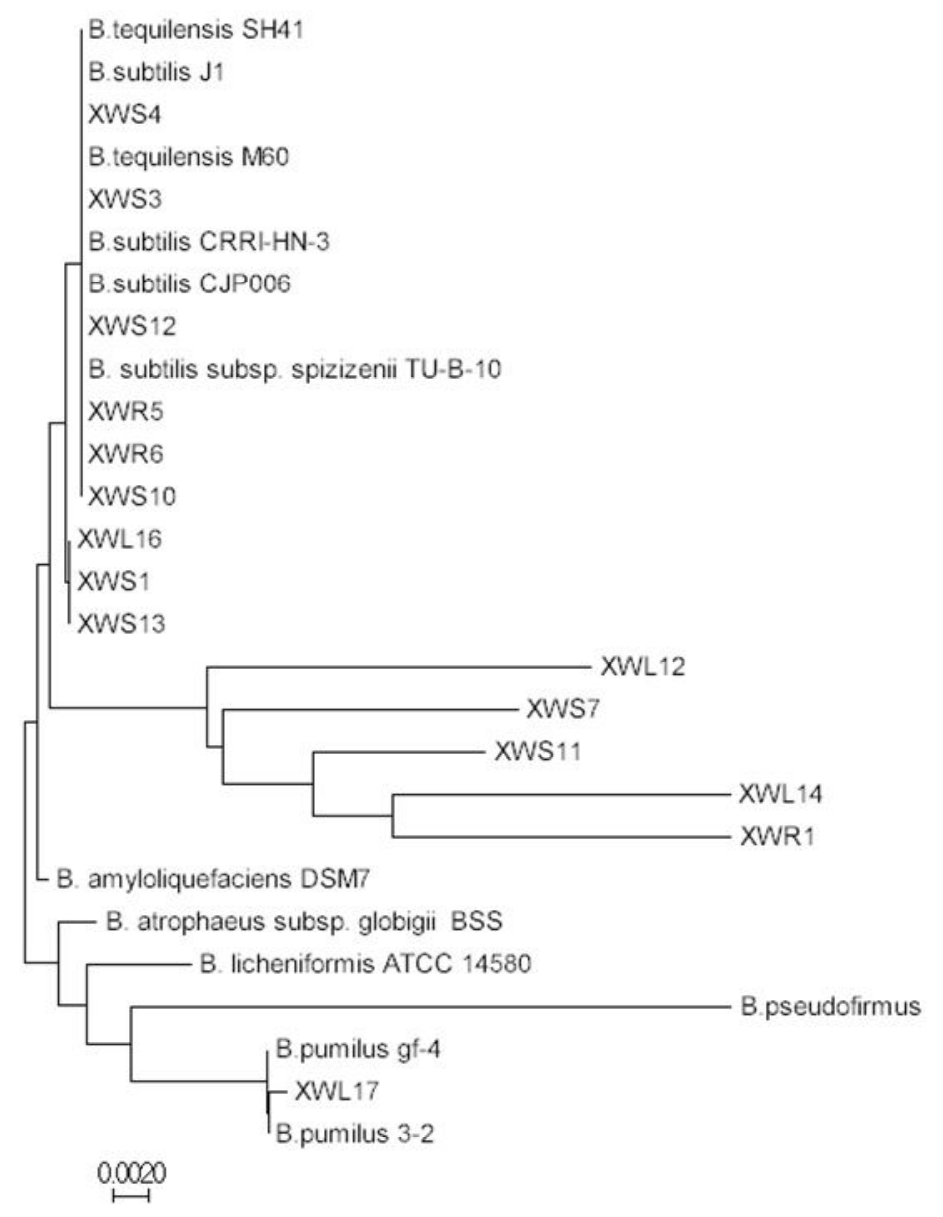

Figure 3.The evolutionary relationships of related species based on $16 \mathrm{~S}$ rDNA and gyrB sequences. 
XWS7 and XWS4 isolated from the stem of walnut, showed preeminent and broad antagonistic effect, the inhibition rate to all assayed pathogens were higher than $40 \%$. Besides, the strain XWR1 which was isolated from the root showed an inhibition effect on the five pathogens with values of inhibition higher than $40 \%$.

Amongst these target pathogens, the cauliflower black spot pathogen $A$. brassicicola showed most susceptibility with most of results that are more than $50 \%$. All the endophytes against their host disease pathogen, their effect is higher than $20 \%$. These results indicate that walnut endophyte might play an important role in pathogen inhibition in the plant. The endophytes from the stem with strains (XWS4 and XWS7) showed a stronger effect than the strains from leave, this might be partially explained that the disease that occurred on leaves more serious than that on the stem.

Besides, from the above test, we assayed these endophytes against Chinese cabbage soft rot pathogen Erwinia carotovora subsp. carotovora and walnut bacterial blight pathogen Xanthomonas arboricola pv. juglandis, they did not show any diameter of inhibition halo (data not shown), suggesting that there is no antagonistic ability to these bacteria.

Abundant endophytic fungi and bacteria exist in planta (Partida et al., 2011). Silva and colleagues isolated 217 bacteria from coffee tissue (Silva et al., 2012), Sid obtained over 500 bacterial isolates from sweet pepper (Sid et al., 2004). However, these endophytes community were with a high diversity in classification and function (Magnani et al., 2010; Vetrivelkalai et al., 2010; Rodriguez Estrada et al., 2012; Lugtenberg et al., 2013). Most common endophytic bacteria reported were $P$. fluorescens, Bacillus, Bradyrhizobium, Azorhizobium and Azospirillum. The endophyte could affect their host plant physiology and ecology through themselves by communicating or interacting with their host cells (Rodriguez Estrada et al., 2012; Brader et al., 2014; King et al., 2016). The main mechanisms of endophyte as biocontrol agents includes the following (Afzal et al., 2014; Aramsirirujiwet et al., 2016; Lugtenberg et al., 2013; Verma and Gange, 2014; Zhao et al., 2014), obtaining mineral nutrient directly, such as fixing nitrogen, dissolving inorganic phosphate, producing siderophore to boost iron absorb; promoting plant growth and development; producing plant hormones; inducing plant assistance related genes expression, for example, endophytic bacteria $P$. putida MGY2 can be used to improve papaya resistant to anthrocanose $C$. gloeosporioides, due to enhance host plant phenylalanine ammonia lyase, catalase and peroxidase levels; direct antagonistic effect against pathogens, and this effect might produce antibiotics, cellular enzymes, such as chitase, cellulase, proteinase and $\beta-1,3$ glucolase and its secondary metabolites.

Many research results have showed that plant endophytes have a strong antagonistic role against plant fungal pathogens. For example, endophytic bacteria isolated from Nicotiana glauca suppress tomato Fusarium wilt $F$. oxysporum f. sp. lycopersici, and reduce yellowing and wilt symptoms to about 94 and $88 \%$, respectively (Aydi Ben Abdallah et al., 2016). Endophytes, probably $B$. subtilis and $B$. licheniformi, decrease pepper leaf spot disease to $53 \%$, microscopy has observed the target fungi cells cavitation, and mycelial dissolved, cytoplasm leak out (Sid et al., 2004).

In this study, the highest inhibition rate was $68.8 \%$, this probably show that walnut endophyte has an important potential application in biocontrol. However, the actual biocontrol effect should be assayed either by placing potted plants or by using field approach for further studies, as well as the mechanism will be conducted in the future.

\section{ACKNOWLEDGEMENTS}

Special thanks to undergraduate students $\mathrm{Wu} \mathrm{Yu}$ and Zhaocai Qian, from College of Life Science and Technology, Hubei Engineering University, who took parts in this experiment. The authors are grateful to Dr. Jose Carlos Huguet-Tapia at University of Florida for his valuable help in writing the manuscript. This research was funded partly by the National Natural Science Foundation of China (31200488) and Hubei Linyunong Science and Technology Ltd. (201808).

\section{REFERENCES}

Adame-Ivarez RM, Mendiola-Soto J, Heil M, 2014. Order of arrival shifts endophyte-pathogen interactions in bean from resistance induction to disease facilitation. FEMS Microbiol Lett, 355: 100-107.

Afzal M, Khan QM, Sessitsch A, 2014. Endophytic bacteria: Prospects and applications for the phytoremediation of organic pollutants. Chemosphere, 117: 232-242.

Alstrom S, Van Vurde JWL, 2001. Endophytic bacteria and biocontrol of plant diseases. Plant Pathog Bact. pp: 60-67.

Andrieu N, Genet JL, Jaworska G, Bompeix G, 2000. In vivo control and in vitro antifungal activity of rhamnolipid $B$, a glycolipid antibiotic, against Phytophthora capsici and Colletotrichum orbiculare. Pest Manag Sci, 56: 1029-1035.

Aramsirirujiwet Y, Gumlangmak C, Kitpreechavanich V, 2016. Studies on antagonistic effect against plant pathogenic fungi from endophytic fungi isolated from Hottuynia cordata Thunb. and screening for siderophore and sndole-3-acetic acid production. KhonKaen Univ Res J, 21(1): 55-66.

Ardanov P, Sessitsch A, Häggman H, Kozyrovska N, Pirttilä AM. 2012. Methylobacterium-induced endophyte community changes correspond with protection of plants against pathogen attack. PLoS One, 7(10): e46802.

Aydi Ben Abdallah R, Mokni-Tlili S, Nefzi A, Jabnoun-Khiareddine $\mathrm{H}$ Daami-Remadi M, 2016. Biocontrol of Fusarium wilt and growth promotion of tomato plants using endophytic bacteria isolated from Nicotiana glauca organs. Biol Control, 97:80-88.

Brader G, Compant S, Mitter B, Trognitz F, Sessitsch A, 2014. Metabolic potential of endophytic bacteria. Curr Opin Biotechnol, 27:30-37.

D'Alessandro M, Erb M, Ton J, Brandenburg A, Karlen D, Zopfi J, Turlings TCJ, 2014. Volatiles produced by soil-borne endophytic bacteria increase plant pathogen resistance and affect tritrophic 
interactions. Plant Cell Environ, 37: 813-826.

De Sassi C, Müller CB, Krauss J, 2006. Fungal plant endosymbionts alter life history and reproductive success of aphid predators. Proc Royal Soc B: Biol Sci, 273(1591): 1301-1306.

Dong XZ, Cai MY, 2001. Common bacteria systematic identification manual. Beijing: Science Press.

King KC, Brockhurst MA, Vasieva O, Paterson S, Betts A, Ford S, Frost CL, Horsburgh MJ, Haldenby S, Hurst GDD, 2016. Rapid evolution of microbe-mediated protection against pathogens in a worm host. The ISME Journal, 10: 1915-1924.

Lugtenberg B, Malfanova N, Kamilova F, Berg G, 2013. Endophytic bacteria with plant growth promoting and biocontrol abilities. Institute Biology of Leiden Faculty of Science Leiden University. 39. doi: 10.1002/9781118297674.

Magnani GS, Didonet CM, Cruz LM, Picheth CF, Pedrosa FO, Souza EM. 2010. Diversity of endophytic bacteria in Brazilian sugarcane. Genet Mol Res, 9: 250-258.

Munif A, Hallmann J, Sikora R. 2012. Isolation of endophytic bacteria from tomato and their biocontrol activities against fungal diseases. Microbiol Indones, 6: 148-156.

Pan D, Mionetto A, Tiscornia S, Bettucci L, 2015. Endophytic bacteria from wheat grain as biocontrol agents of Fusarium graminearum and deoxynivalenol production in wheat. Mycotoxin Res, 31: 137-143.

Partida-Martínez LP, Heil M, 2011. The microbe-free plant: fact or artifact? Front Plant Sci, 2: 100.

Rakotoniriana EF, Rafamantanana $M$, Randriamampionona D, Rabemanantsoa C, Urveg-Ratsimamanga S, El Jaziri M, Munaut F, Corbisier AM, Quetin-Leclercq J, Declerck S, 2013. Study in vitro of the impact of endophytic bacteria isolated from Centella asiatica on the disease incidence caused by the hemibiotrophic fungus Colletotrichum higginsianum. Antonie van Leeuwenhoek, 103: 121133.

Rodriguez Estrada AE, Jonkers W, Corby Kistler H, May G, 2012. Interactions between Fusarium verticillioides, Ustilago maydis, and Zea mays: An endophyte, a pathogen, and their shared plant host. Fungal Genet Biol, 49:578-587.

Saitou N, Nei M, 1987. The neighbor-joining method: A new method for reconstructing phylogenetic trees. Mol Biol Evol, 4: 406-425.

Sid A, Ezziyyani M, Egea-Gilabert C, Candela ME, 2004. Selecting bacterial strains for use in the biocontrol of diseases caused by Phytophthora capsici and Alternaria alternata in sweet pepper plants. Biologia Plantarum, 47(4): 569-574.

Silva HSA, Tozzi JPL, Terrasan CRF, Bettiol W, 2012. Endophytic microorganisms from coffee tissues as plant growth promoters and biocontrol agents of coffee leaf rust. Biol Control, 63: 62-67.

Verma VC, Gange AC, 2014. Advances in Endophytic Research. Springer-India. pp: 321-333.

Vetrivelkalai P, Sivakumar M, Jonathan EI, 2010. Biocontrol potential of endophytic bacteria on Meloidogyne incognita and its effect on plant growth in bhendi. J Biopestic, 3: 452-457.

Wu HY, Zheng MY, Min XU, Wang MQ, Hao XJ, 2015. Antifungal activity of the fermentation liquid of walnut endophytic bacteria HT-6. J Shanxi Agric Sci, 43(10): 1315-1328.

Xu WT, Zhai MZ, Wang W, Gao ZH, Li XM, 2008. Studies on endophytic fungi from Juglans regia L. II. Antimicrobial activity of the fermentation metabolites produced from an endophyte G8 of walnut. Acta Agriculturae Boreali-occidentalis Sinica, 17(1): 82-87.
Zhai MZ, Wen XQ, Liu F, Gao ZH, Zhang YL, 2009. Isolation of endophytic fungi from walnut and their anti-fungal activities. J Northwest For Univ, 24(3): 144-147.

Zhang Q, Li Y, Xia L, 2014. An oleaginous endophyte Bacillus subtilis HB1310 isolated from thin-shelled walnut and its utilization of cotton stalk hydrolysate for lipid production. Biotechnol Biofuels, 7: 152.

Zhao Y, Selvaraj JN, Xing F, Zhou L, Wang Y, Song H, Tan X, Sun L, Sangare L, Folly YME, Liu Y, 2014. Antagonistic action of Bacillus subtilis strain SG6 on Fusarium graminearum. PLOS ONE, 9(3): e92486.

Citation: Fu B, Zou L, 2018. Antagonism of Walnut endophytic bacteria against six crop pathogenic fungi and its diversity. Microbiol Res Int, 6(3): 40-48. 